\title{
Variation in transfusion rates within a single institution: Exploring the effect of differing practice patterns on the likelihood of blood product transfusion in patients undergoing cardiac surgery
}

\author{
Claudia Cote, BSc, ${ }^{a}$ Jeffrey B. MacLeod, BSc, ${ }^{\mathrm{b}}$ Alexandra M. Yip, MSc, ${ }^{\mathrm{b}}$ Maral Ouzounian, MD, PhD, \\ Craig D. Brown, MD, ${ }^{b}$ Rand Forgie, MD, ${ }^{b}$ Marc P. Pelletier, MD, MSc, ${ }^{b}$ and Ansar Hassan, MD, $\mathrm{PhD}^{\mathrm{b}}$
}

\begin{abstract}
Objectives: Rates of perioperative transfusion vary widely among patients undergoing cardiac surgery. Few studies have examined factors beyond the clinical characteristics of the patients that may be responsible for such variation. The purpose of this study was to determine whether differing practice patterns had an impact on variation in perioperative transfusion at a single center.
\end{abstract}

Methods: Patients who underwent cardiac surgery at a single center between 2004 and 2011 were considered. Comparisons were made between patients who had received a perioperative transfusion and those who had not from the clinical factors at baseline, intraoperative variables, and differing practice patterns, as defined by the surgeon, anesthesiologist, perfusionist, and the year in which the procedure was performed. The risk-adjusted effect of these factors on perioperative transfusion rates was determined using multivariable regression modeling techniques.

Results: The study population comprised 4823 patients, of whom 1929 (40.0\%) received a perioperative transfusion. Significant variation in perioperative transfusion rates was noted between surgeons (from $32.4 \%$ to $51.5 \%, P<.0001$ ), anesthesiologists (from $34.4 \%$ to $51.9 \%, P<.0001$ ) and across year (from $28.2 \%$ in 2004 to $48.8 \%$ in $2008, P<.0001$ ). After adjustment for baseline and intraoperative variables, surgeon, anesthesiologist, and year of procedure were each found to be independent predictors of perioperative transfusion.

Conclusions: Differing practice patterns contribute to significant variation in rates of perioperative transfusion within a single center. Strategies aimed at reducing overall transfusion rates must take into account such variability in practice patterns and account for nonclinical factors as well as known clinical predictors of blood transfusions. (J Thorac Cardiovasc Surg 2015;149:297-302)

See related commentary on pages 303-4.

Transfusion of blood products among patients undergoing cardiac surgery has been associated with increased shortand long-term morbidity including incision infection, ${ }^{1,2}$ pneumonia, ${ }^{2,3}$ renal dysfunction, ${ }^{4-6}$ severe sepsis, ${ }^{2,6}$ and mortality. ${ }^{7,8}$ Efforts to better understand predictors of transfusion and to reduce rates of perioperative transfusion have resulted in the development of several

\footnotetext{
From the Dalhousie Medicine New Brunswick ${ }^{\mathrm{a}}$; Cardiovascular Research

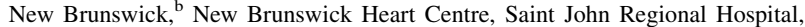
Saint John, New Brunswick, Canada; and Toronto General Hospital, ${ }^{\mathrm{c}}$ University of Toronto, Toronto, Ontario, Canada.

Disclosures: M.P. Pelletier has received consultancy fees and has lectured for Edwards LifeSciences. All other authors have nothing to disclose with regard to commercial support.

Received for publication Jan 23, 2014; revisions received Aug 25, 2014; accepted for publication Sept 4, 2014; available ahead of print Oct 7, 2014

Address for reprints: Ansar Hassan, MD, PhD, Department of Cardiac Surgery, New Brunswick Heart Centre, Saint John Regional Hospital, 400 University Ave, PO Box 2100, Saint John, New Brunswick, Canada E2L 4L2 (E-mail: ahassan@dal.ca).

0022-5223/ $\$ 36.00$

Copyright (C) 2015 by The American Association for Thoracic Surgery

http://dx.doi.org/10.1016/j.jtcvs.2014.09.004
}

quality improvement initiatives, ${ }^{9-11}$ Many of these initiatives have focused on patient-specific predictors of transfusion, including increased age, female sex, lower body mass index (BMI), reduced preoperative hematocrit, use of platelet-inhibiting drugs, and surgical acuity. ${ }^{9,12}$

Despite these efforts, studies have shown that significant interinstitutional variability in blood transfusion practices persists, ${ }^{13-15}$ suggesting that factors other than patientspecific variables are at play in determining rates of transfusion. Jin and colleagues ${ }^{16}$ demonstrated that after adjusting for differences in patient risk factors, there was a significant effect of hospital culture on transfusion rates at an institution.

To date, few studies have examined the effect that differing individual practice patterns have on variation in transfusion rates, especially within a single institution. ${ }^{16-18}$ A more thorough understanding of these practice pattern differences may lead to strategies that can reduce rates of transfusion within an institution and thus limit interinstitutional variability. The purpose of this study was to determine the effect of differing practice patterns on variation in perioperative transfusion rates at a single institution. 


$$
\begin{array}{ll}
\text { Abbreviations and Acronyms } \\
\text { ASA } & =\text { acetyl salicylic acid } \\
\text { BMI } & =\text { body mass index } \\
\text { CABG } & =\text { coronary artery bypass graft } \\
\text { CPB } & =\text { cardiopulmonary bypass } \\
\text { CryoPPT } & =\text { cryoprecipitate } \\
\text { FEIBA } & =\text { factor } 8 \text { inhibitor bypassing activity } \\
\text { FFP } & =\text { fresh frozen plasma } \\
\text { MI } & =\text { myocardial infarction } \\
\text { NYHA } & =\text { New York Heart Association } \\
\text { PLT } & =\text { platelets }
\end{array}
$$

\section{PATIENTS AND METHODS \\ Patient Population}

All patients who underwent cardiac surgery at the Saint John Regional Hospital, Saint John, New Brunswick (Canada) from April 1, 2004, to September 30, 2011, were included in this study. Patients who underwent an emergency or off-pump procedure were excluded from the final study sample. No strict intraoperative transfusion protocol was implemented for the duration of the study. Postoperatively, the only guideline in place was for administration of packed red blood cells (pRBC) for a hemoglobin concentration less than $70 \mathrm{~g} / \mathrm{L}$. The number of units to be given or the target hemoglobin level was not specified in these guidelines. With respect to transfusion of coagulation products, these were administered subjectively depending on the amount of blood loss experienced or the perception that a coagulopathy was responsible for this blood loss.

Ethics approval was obtained from the Horizon Health Network Ethics Review Board with a waiver of patient consent as the study was retrospective in nature and identification of patients was not necessary.

\section{Data Sources}

Patients were identified from the New Brunswick Heart Centre Cardiac Surgery database, a detailed observational clinical registry that prospectively collects information on pre-, intra-, and postoperative characteristics for all patients undergoing cardiac surgery at the Saint John Regional Hospital. Detailed transfusion data were obtained from the institutional laboratory information system, which tracks the date, time, amount, and location of all transfusions of pRBC and coagulant products.

\section{Variable Definitions}

The following baseline clinical characteristics were taken into consideration: age, sex, BMI, smoking history, diabetes, hypercholesterolemia, renal failure (defined as serum creatinine $>176 \mu \mathrm{mol} / \mathrm{L}$ ), hypertension, chronic obstructive pulmonary disease, peripheral vascular disease, cerebrovascular disease, previous cardiac surgery, recent myocardial infarction (MI) ( $\leq 21$ days), congestive heart failure, unstable angina, atrial fibrillation, preoperative medications (acetyl salicylic acid [ASA], angiotensin-converting enzyme inhibitors, anticoagulants, $\beta$-blockers, cholesterol-lowering agents), New York Heart Association (NYHA) functional class (IV vs I/II/III), ejection fraction less than $40 \%$, and urgency status (urgent vs elective). Data on the use of non-ASA antiplatelet medications, including clopidogrel, ticlodipine, and abciximab, were not available for the entire study duration and were thus not included in the analysis.

Intraoperative variables of interest included procedure type (isolated coronary artery bypass graft [CABG], isolated valve, $\mathrm{CABG}+$ valve, or other $\pm \mathrm{CABG} \pm$ valve), cardiopulmonary bypass ( $\mathrm{CPB})$ time, baseline hematocrit less than $40 \%$ before initiating CPB, insertion of an intra-aortic balloon pump, and administration of inotropes on transfer from the operating room to the intensive care unit.

Practice patterns were characterized by the attending surgeon, anesthesiologist, and perfusionist as well as the year in which the procedure was performed. Although our institution follows an open intensive care unit model, dedicated intensivists were not involved in the postoperative management of patients and were therefore not included in the analysis. Furthermore, the assignment of surgeon and anesthesiologist at our institution is random, and therefore no surgeon-anesthesiologist teams existed, indicating the relative independence of these variables. The year was chosen as a variable to reflect the changes in transfusion practices that may have existed over time but could not be attributed to differences in patient-specific clinical factors or individual practice patterns. Examples of such changes could include a mandated change in transfusion culture within an institution through the adoption of strict transfusion protocols or new onset shortages of blood products resulting from changes in blood bank supply.

The primary outcome of interest, perioperative transfusion, was defined as the administration of 1 or more units of pRBC, fresh frozen plasma (FFP), platelets (PLT), cryoprecipitate (CryoPPT), and/or factor 8 inhibitor bypassing activity (FEIBA) intraoperatively or during the first 24 hours after surgery. Transfusion of recombinant factor VIIa was not considered because 2 of the 5 surgeons included in the study did not use this product during the study period.

\section{Statistical Analysis}

Patients who received a perioperative transfusion were compared with those who did not based on the baseline characteristics, intraoperative factors, and practice pattern variables. The $\chi^{2}$ test was used to compare categorical variables as well as transfusion rates by surgeon, anesthesiologist, perfusionist, and year. A multivariable logistic regression model was constructed from the baseline and intraoperative characteristics using perioperative transfusion as the outcome of interest. The nonparsimonious risk-adjusted predictive model identified those clinical and nonclinical variables that best predicted whether or not a patient was likely to receive a perioperative transfusion.

All statistical analyses were performed using SAS v 9.3 (SAS Institute, Inc, Cary, NC).

\section{RESULTS}

The final study population included 4823 patients, of whom $1929(40.0 \%)$ received a perioperative transfusion. Of the 1929 patients who received a transfusion, 1685 $(87.4 \%)$ received pRBCs and $889(46.1 \%)$ received 1 or more coagulation products in the form of FFP, PLT, CryoPPT, or FEIBA.

\section{Baseline Characteristics}

Patients who received a perioperative transfusion were more likely to be older and female, have a BMI less than $25 \mathrm{~kg} / \mathrm{m}^{2}$, have more comorbid illnesses, have been on anticoagulants, have had NYHA class IV symptoms, have experienced a recent MI, have undergone previous cardiac surgery, and have presented with greater surgical acuity (Table 1).

\section{Intraoperative Variables}

Intraoperatively, patients who had undergone more complex procedures, had experienced prolonged bypass 
TABLE 1. Patient characteristics associated with transfusion of any blood product

\begin{tabular}{|c|c|c|c|c|}
\hline Variable & Total & Transfused $(N=1929)$ & Not transfused $(N=2894)$ & $P$ value \\
\hline Age $\geq 70 y$ & 1746 & $984(51.0)$ & $762(26.3)$ & $<.0001$ \\
\hline Female sex & 1203 & $872(45.2)$ & $331(11.4)$ & $<.0001$ \\
\hline BMI & & & & $<.0001$ \\
\hline$<25 \mathrm{~kg} / \mathrm{m}^{2}$ & 1096 & $616(31.9)$ & $480(16.6)$ & \\
\hline $25-30 \mathrm{~kg} / \mathrm{m}^{2}$ & 2072 & $792(41.3)$ & $1276(44.1)$ & \\
\hline$\geq 30 \mathrm{~kg} / \mathrm{m}^{2}$ & 1655 & $517(26.8)$ & $1138(39.3)$ & \\
\hline Smoking history & 2556 & $934(48.4)$ & $1622(56.1)$ & $<.0001$ \\
\hline Diabetes & 1493 & $653(33.9)$ & $840(29.0)$ & .0004 \\
\hline Hypercholesterolemia & 3604 & $1401(72.6)$ & $2203(76.1)$ & .0062 \\
\hline Renal failure & 139 & $115(6.0)$ & $24(0.8)$ & $<.0001$ \\
\hline Hypertension & 3261 & $1375(71.3)$ & $1886(65.2)$ & $<.0001$ \\
\hline COPD & 429 & $209(10.8)$ & $220(7.6)$ & .0001 \\
\hline Peripheral vascular disease & 329 & $174(9.0)$ & $155(5.4)$ & $<.0001$ \\
\hline Cerebrovascular disease & 439 & $235(12.2)$ & $204(7.1)$ & $<.0001$ \\
\hline Previous cardiac surgery & 132 & $86(4.5)$ & $46(1.6)$ & $<.0001$ \\
\hline $\mathrm{MI} \leq 21 \mathrm{~d}$ & 1002 & $440(22.8)$ & $562(19.4)$ & .0045 \\
\hline Congestive heart failure & 728 & $459(23.8)$ & $269(9.3)$ & $<.0001$ \\
\hline Angina & & & & $<.0001$ \\
\hline Stable & 840 & $285(14.8)$ & $555(19.2)$ & \\
\hline Unstable & 2358 & $894(46.4)$ & $1464(50.6)$ & \\
\hline Atrial fibrillation & 440 & $266(13.8)$ & $174(6.0)$ & $<.0001$ \\
\hline \multicolumn{5}{|l|}{ Medications } \\
\hline ASA & 3864 & $1501(77.8)$ & $2363(81.7)$ & .001 \\
\hline ACE inhibitors & 2537 & $977(50.7)$ & $1560(53.9)$ & .0265 \\
\hline Anticoagulants & 1409 & 649 (33.6) & $760(26.3)$ & $<.0001$ \\
\hline$\beta$-Blockers & 3481 & $1350(70.0)$ & $2131(73.6)$ & .0056 \\
\hline Cholesterol-lowing agents & 3536 & $1354(70.2)$ & $2182(75.4)$ & $<.0001$ \\
\hline NYHA IV & 1404 & $646(33.5)$ & $758(26.2)$ & $<.0001$ \\
\hline $\mathrm{EF}<40 \%$ & 482 & $248(12.9)$ & $234(8.1)$ & $<.0001$ \\
\hline Status & & & & $<.0001$ \\
\hline Elective & 2210 & $796(41.3)$ & $1414(48.9)$ & \\
\hline Urgent & 2613 & $1133(58.7)$ & $1480(51.1)$ & \\
\hline
\end{tabular}

Variables expressed as the number of cases (percentage of group). $P$ values were obtained using the $\chi^{2}$ test. $B M I$, Body mass index; $C O P D$, chronic obstructive pulmonary disease $M I$, myocardial infarction; $A S A$, acetyl salicylic acid; $A C E$ inhibitor, angiotensin-converting enzyme inhibitor; $N Y H A I V$, New York Heart Association class IV; $E F$, ejection fraction.

times, had a lower prebypass hematocrit, had an intra-aortic balloon pump inserted, or were on inotropic support on transfer from the operating room were more likely to have received a perioperative transfusion (Table 2).

\section{Practice Patterns}

A total of 5 attending surgeons, 7 anesthesiologists, and 7 perfusionists were identified as practitioners during the study period. When individual practice patterns were considered, significant variation in perioperative transfusion rates was noted between surgeons (range, 32.4\%-51.5\%; $P<.0001$ ) and anesthesiologists (range, 34.4\%-51.9\%; $P<.0001)$, and across year $(28.2 \%$ in 2004 to $48.8 \%$ in 2008; $P<.0001$ ) (Figure 1). There was no significant variation in perioperative transfusion rates among perfusionists (range, 37.1\%-42.1\%;P=.56). When unadjusted perioperative transfusion rates of different surgeons and anesthesiologists and perfusionist were analyzed over time, an overall increase in rates of transfusion between 2007 and 2009 was observed irrespective of the practitioner (Figure 2).

\section{Risk-Adjusted Analyses}

After adjustment for differences in baseline clinical characteristics and case mix, the risk-adjusted likelihood of receiving a perioperative transfusion differed significantly among surgeons and anesthesiologists and across years (Table 3). No risk-adjusted differences existed between perfusionists. When rates of transfusion of perioperative $\mathrm{pRBC}$ and perioperative coagulation products were examined separately, the risk-adjusted effect of differing practice patterns among anesthesiologists and year persisted for transfusion of both $\mathrm{pRBC}$ and perioperative coagulation products. However, the effect of individual surgeon practice pattern on these 2 outcomes differed. Although pronounced differences existed between surgeons in the rates of transfusion of perioperative coagulation products, no differences were noted between 
TABLE 2. Intraoperative variables associated with transfusion of any blood product

\begin{tabular}{lrrrc}
\hline \multicolumn{1}{c}{ Variable } & Total & $\begin{array}{c}\text { Transfused } \\
(\mathbf{N}=\mathbf{1 9 2 9})\end{array}$ & $\begin{array}{c}\text { Not } \\
\text { transfused } \\
(\mathbf{N}=\mathbf{2 8 9 4})\end{array}$ & $\begin{array}{c}\boldsymbol{P} \\
\text { value }\end{array}$ \\
\hline Procedure & & & & $<.0001$ \\
$\quad$ Isolated CABG & 3236 & $1014(52.6)$ & $2222(76.8)$ & \\
Isolated valve & 579 & $266(13.8)$ & $313(10.8)$ & \\
CABG + valve & 519 & $360(18.7)$ & $159(5.5)$ & \\
$\quad$ Other \pm CABG \pm valve & 489 & $289(15.0)$ & $200(6.9)$ & \\
CPB time & & & & $<.0001$ \\
$\leq 90$ min & 1843 & $565(29.3)$ & $1278(44.2)$ & \\
$>90$ min & 2980 & $1364(70.7)$ & $1616(55.8)$ & \\
Hematocrit & & & & $<.0001$ \\
$\quad<40 \%$ & 2993 & $1556(80.7)$ & $1437(49.7)$ & \\
$\geq 40 \%$ & 1830 & $373(19.3)$ & $1457(50.4)$ & \\
Inotropes & 547 & $361(18.7)$ & $186(6.4)$ & $<.0001$ \\
IABP insertion & 134 & $88(4.4)$ & $46(1.5)$ & $<.0001$ \\
\hline Variables are expressed as the number of cases (percentage of group). $P$ values where \\
obtained using the $\chi^{2}$ test. $C A B G$, Coronary artery bypass graft; $C P B$, cardiopulmo- \\
nary bypass; IABP, intra-aortic balloon pump. & &
\end{tabular}

surgeons in the rates of transfusion of perioperative $\mathrm{pRBC}$ (Table 3).

\section{COMMENT}

This study set out to determine the effect of differing practice patterns on the rates of perioperative transfusion at a single institution among patients undergoing cardiac surgery. After adjustment for clinical characteristics, surgeon, anesthesiologist, and the year in which the procedure was performed were identified as independent predictors of perioperative transfusion.

Jin and colleagues, ${ }^{16}$ in a review of transfusion practices of 42 surgeons at 12 hospitals, found that frequency, amount, timing, and blood component usage were different between facilities but relatively similar for surgeons within a facility. They were able to determine that $70 \%$ of the variation in pRBC transfusion could be explained by the hospital effect, whereas the surgeon contributed only $30 \%$. In our study, focusing on variation within a single hospital, both surgeon and anesthesiologist emerged as independent predictors of transfusion of perioperative blood products. Further differences were noted when the rates of perioperative transfusion of $\mathrm{pRBC}$ and coagulation products were examined separately. These findings highlight the subjective nature of transfusion practices and the role that individual practice patterns play in creating variability in transfusion rates. In particular, the presence of an effect of surgeon on the rate of perioperative transfusion of coagulation products in the absence of any surgeon-specific effect on the rate of perioperative transfusion of pRBC suggest that although transfusion with $\mathrm{pRBC}$ at our institution may have been more goal directed and hence objective, the transfusion of coagulation products may have been decidedly less
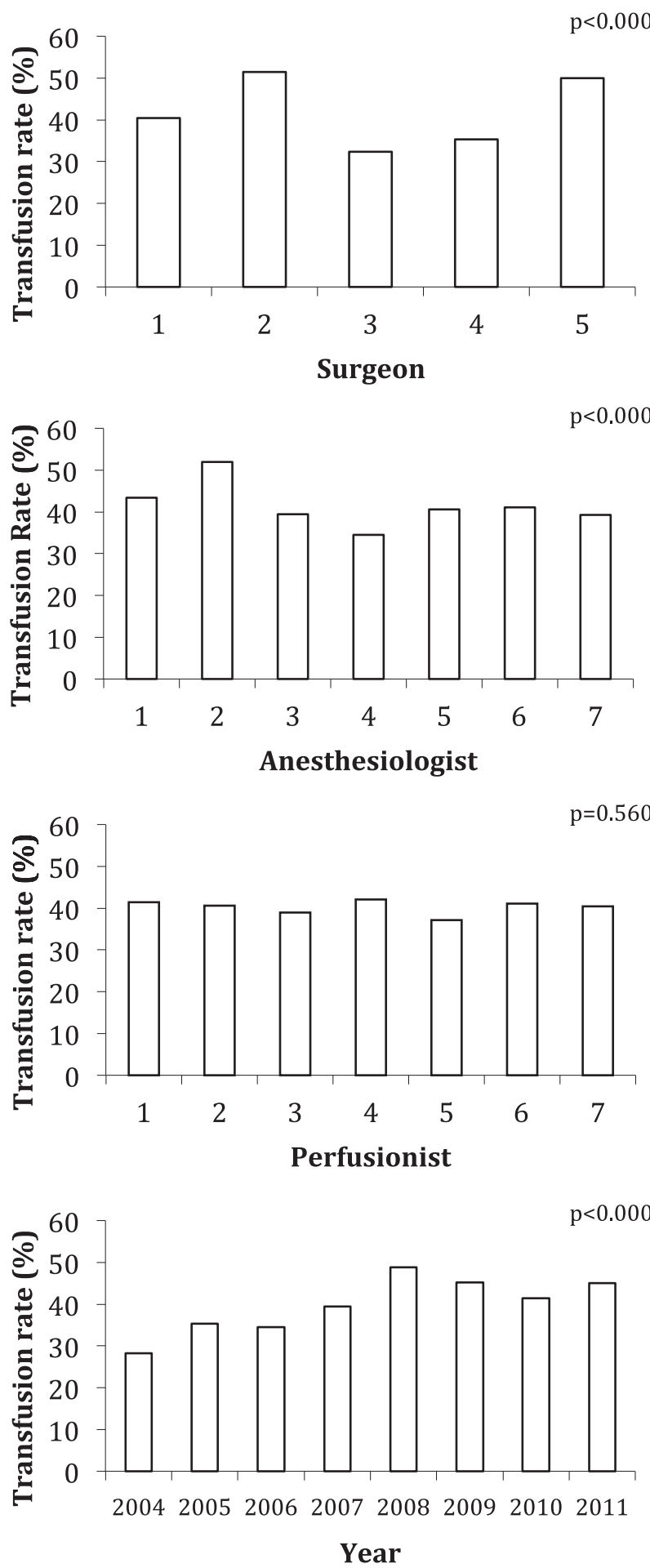

FIGURE 1. Variability in unadjusted transfusion rates by surgeon, anesthesiologist, perfusionist and year.

objective and based more on a feeling that the patient required coagulation products because they were "wet" or "oozy." Perhaps, by introducing more objective measures of coagulopathy, such as point-of-care thromboelastography, transfusion of coagulation products may become 

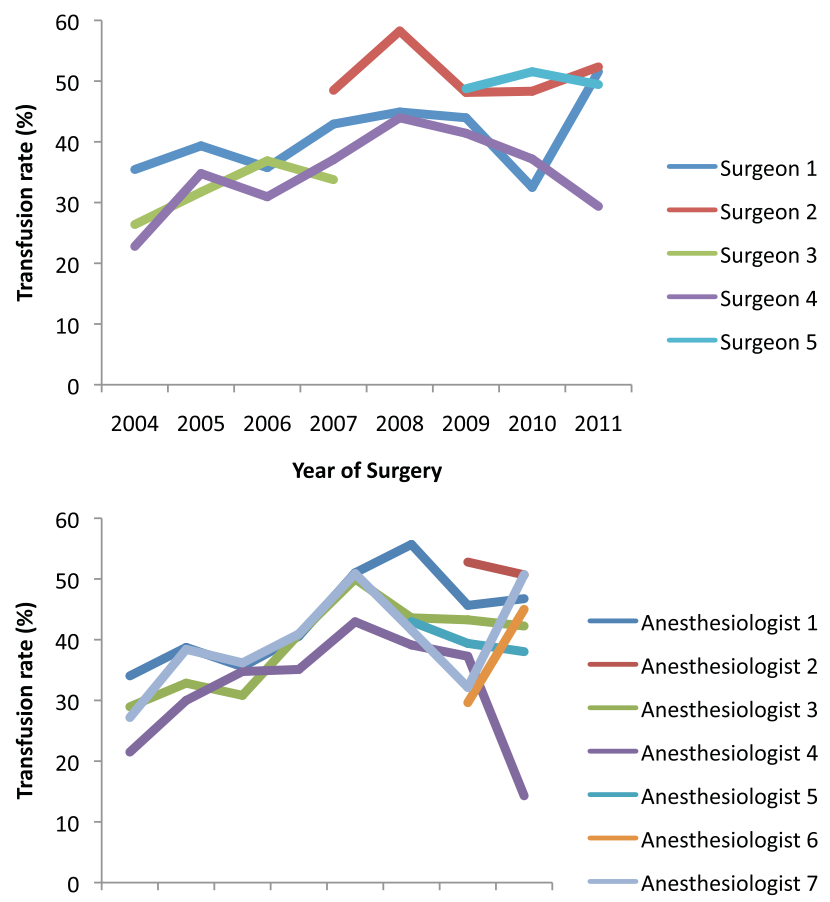

20042005200620072008200920102011

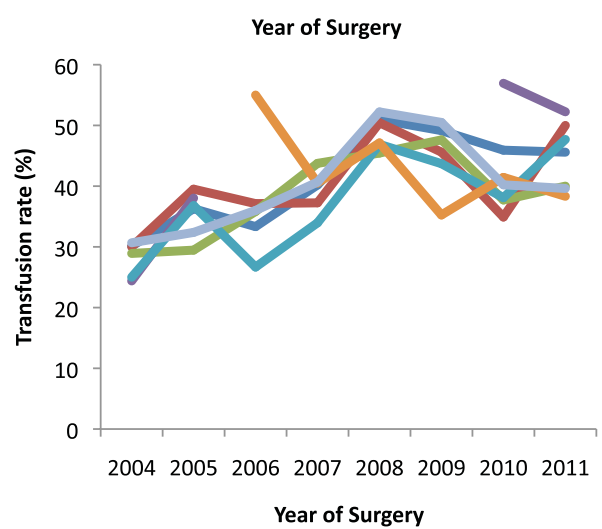

FIGURE 2. Unadjusted rates of transfusion over time by individual surgeon, anesthesiologist, and perfusionist.

more goal directed and the variation in rates of perioperative transfusion of coagulation products less pronounced.

In addition to the variability in transfusion rates noted among surgeons and anesthesiologists, the rates of blood transfusion were found to have changed significantly over time, with increased probability of transfusion noted in all years compared with 2004. During the course of the study, adjusted rates of transfusion seemed to peak between 2007 and 2009. In studies purporting the negative effects of perioperative transfusion, 7,8 one would have expected consistent practices or even a decrease in transfusion rates over time. Many factors may be responsible for this trend. First, an unwritten or informal change in transfusion policies during the time period could have had an effect on transfusion rates. Second, 1 surgeon retired in 2007
TABLE 3. Independent effect of surgeon, anesthesiologist, perfusionist, and year on the likelihood of perioperative transfusion of any blood product, pRBC, or coagulation product*

\begin{tabular}{|c|c|c|c|}
\hline \multirow[b]{2}{*}{ Variable } & \multicolumn{3}{|c|}{ Odds ratio $(95 \% \mathrm{CI})$} \\
\hline & $\begin{array}{c}\text { Any blood } \\
\text { transfusion }\end{array}$ & $\begin{array}{c}\text { pRBC } \\
\text { transfusion }\end{array}$ & $\begin{array}{c}\text { Coagulation } \\
\text { product } \\
\text { transfusion } \\
\end{array}$ \\
\hline \multicolumn{4}{|l|}{ Surgeon } \\
\hline 1 & $1.01(0.78,1.31)$ & $0.81(0.62,1.07)$ & $2.54(1.77,3.65)$ \\
\hline 2 & $1.54(1.12,2.11)$ & $0.92(0.66,1.30)$ & $3.97(2.63,5.98)$ \\
\hline 3 & 1 (Ref) & 1 (Ref) & 1 (Ref) \\
\hline 4 & $0.95(0.74,1.22)$ & $0.82(0.62,1.07)$ & $1.78(1.23,2.57)$ \\
\hline 5 & $1.59(1.07,2.35)$ & $1.18(0.78,1.79)$ & $5.20(3.26,8.31)$ \\
\hline \multicolumn{4}{|c|}{ Anesthesiologist } \\
\hline 1 & $2.18(1.74,2.73)$ & $2.05(1.61,2.61)$ & $1.40(1.09,1.81)$ \\
\hline 2 & $2.34(1.49,3.67)$ & $2.26(1.40,3.64)$ & $2.15(1.36,3.41)$ \\
\hline 3 & $1.30(1.04,1.64)$ & $1.09(0.86,1.40)$ & $1.28(0.98,1.67)$ \\
\hline 4 & 1 (Ref) & 1 (Ref) & 1 (Ref) \\
\hline 5 & $1.56(1.08,2.25)$ & $1.66(1.12,2.45)$ & $1.25(0.83,1.86)$ \\
\hline 6 & $1.18(0.66,2.12)$ & $1.10(0.60,2.03)$ & $1.02(0.53,1.97)$ \\
\hline 7 & $1.36(1.07,1.71)$ & $1.24(0.97,1.59)$ & $1.20(0.92,1.59)$ \\
\hline \multicolumn{4}{|l|}{ Perfusionist } \\
\hline 1 & $1.10(0.85,1.41)$ & $1.09(0.83,1.42)$ & $1.21(0.90,1.63)$ \\
\hline 2 & $1.05(0.81,1.34)$ & $0.98(0.75,1.28)$ & $1.12(0.83,1.50)$ \\
\hline 3 & $1.02(0.80,1.32)$ & $0.96(0.73,1.25)$ & $1.02(0.76,1.38)$ \\
\hline 4 & $1.17(0.82,1.68)$ & $0.90(0.61,1.31)$ & $1.47(0.98,2.21)$ \\
\hline 5 & 1 (Ref) & 1 (Ref) & 1 (Ref) \\
\hline 6 & $1.06(0.80,1.41)$ & $1.14(0.84,1.54)$ & $1.33(0.96,1.84)$ \\
\hline 7 & $1.22(0.94,1.58)$ & $1.08(0.82,1.43)$ & $1.49(1.10,2.02)$ \\
\hline \multicolumn{4}{|l|}{ Year } \\
\hline 2004 & 1 (Ref) & 1 (Ref) & 1 (Ref) \\
\hline 2005 & $1.56(1.14,2.14)$ & $1.62(1.16,2.27)$ & $1.12(0.75,1.66)$ \\
\hline 2006 & $1.86(1.37,2.62)$ & $1.86(1.32,2.63)$ & $1.32(0.88,1.98)$ \\
\hline 2007 & $2.56(1.85,3.53)$ & $2.60(1.85,3.67)$ & $1.55(1.04,2.32)$ \\
\hline 2008 & $3.56(2.53,5.01)$ & $3.64(2.53,5.23)$ & $1.79(1.20,2.67)$ \\
\hline 2009 & $3.48(2.45,4.95)$ & $3.90(2.68,5.67)$ & $1.32(0.87,1.99)$ \\
\hline 2010 & $2.05(1.44,2.92)$ & $1.96(1.34,2.87)$ & $1.42(0.94,2.15)$ \\
\hline 2011 & $1.92(1.29,2.87)$ & $1.90(1.24,2.91)$ & $0.84(0.53,1.35)$ \\
\hline
\end{tabular}

pRBC, Packed red blood cells; $C I$, confidence interval. *Adjusted for age, sex, body mass index, smoking history, diabetes, hypercholesterolemia, renal failure, hypertension, chronic obstructive pulmonary disease, peripheral vascular disease, cerebrovascular disease, previous cardiac surgery, myocardial infarction $\leq 21$ days, congestive heart failure, angina, atrial fibrillation, New York Heart Association functional class, ejection fraction $<40 \%$, status, procedure, inotropes use, cardiopulmonary bypass time $>90$ minutes, and hematocrit $<40 \%$.

and 2 new surgeons entered the practice in 2007 and 2009, respectively. This change in the composition of the department may have had an effect on the style of practice and subsequent rates of transfusion during the study period. Similarly, changes took place in the anesthesiology and clinical perfusion departments during that period. However, when unadjusted rates of transfusion by each individual surgeon, anesthesiologist, and perfusionist were examined, increases in transfusion rates by individual practitioners between 2007 and 2009 were consistently noted. This pattern suggested that there 
was a possible overall shift in hospital culture driving changes in transfusion practices over time.

The novel findings presented in this study emphasize the need for future studies examining the rates and predictors of blood transfusion to account for interpractitioner variability as well as the year in which the surgery is performed. Furthermore, this study supports the implementation of strict institutional transfusion guidelines so that all practitioners at a single institution administer blood products in a more objective and goal-oriented fashion.

However, this study is not without its limitations. First, although ASA use was adjusted for, use of other antiplatelets, including the doses or duration of use, was not examined. Second, the effect of case volume, level of experience, or location of residency and/or fellowship training on the likelihood of an individual surgeon or anesthesiologist choosing transfusion was not examined. Third, the amount of perioperative bleeding, which has been shown to affect the decision on transfusion, ${ }^{19}$ was not recorded. Fourth, the retrospective nature of this study did not allow us to determine who was responsible for deciding on transfusion or not and what the reason for the transfusion was. In general, at our institution, the decision on intraoperative transfusion is made jointly by the surgeon, anesthesiologist, and perfusionist, whereas postoperatively, it is predominately the surgeon who decides. However, for the purposes of this study, not knowing who initiated the transfusion and why impeded our ability to explain the interpractitioner variability observed. Recently, Zaffar and colleagues ${ }^{19}$ published a study in which focused physician questionnaires were administered to assess factors influencing the decision to transfuse platelets during cardiac surgery. The respondents reported bleeding, bleeding in the presence of thrombocytopenia, type of surgical procedure, and preoperative antiplatelet use as significant factors. Unfortunately, the questionnaire did not address differences in triggers for platelet transfusion between practitioners. A questionnaire considering both objective and subjective triggers for transfusion could ideally be administered to surgeons and anesthesiologists in a prospective manner after the transfusion of any blood product. The results of such a questionnaire would shed light on the objective clinical factors influencing decisions on transfusion and the differences in the triggers that are likely to exist based on nonclinical subjective factors such as previous experience and personal bias.

In conclusion, we have demonstrated the significant effect of differing practice patterns on variation in the rates of perioperative transfusion within a single center. Based on these findings, future studies regarding the use of blood products should account for nonclinical factors such as practitioner and year of surgery. Furthermore, when attempting to reduce the overall rate of perioperative transfusion, strategies aimed at better understanding and ultimately reducing interpractitioner variability in transfusion practices must be considered.

\section{References}

1. Habib RH, Zacharias A. Factors predisposing to median sternotomy complications: deep vs superficial infection. Chest. 1996;110:1173-8.

2. Horvath KA, Acker MA, Chang H, Bagiella E, Smith PK, Iribarne A, et al. Blood transfusion and infection after cardiac surgery. Ann Thorac Surg. 2013;95: 2194-201.

3. Leal-Noval SR, Marquez-Vácaro JA, García-Curiel A, Camacho-Laraña P, Rincón-Ferrari MD, Ordoñez-Fernández A, et al. Nosocomial pneumonia in patients undergoing heart surgery. Crit Care Med. 2000;28:935-40.

4. Koch CG, Li L, Duncan AI, Mihaljevic T, Cosgrove DM, Loop FD, et al. Morbidity and mortality risk associated with red blood cell and blood-component transfusion in isolated coronary artery bypass grafting. Crit Care Med. 2006;34:1608-16.

5. Loor G, Rajeswaran J, Li L, Sabik JF III, Blackstone EH, McCrae KR, et al. The least of 3 evils: exposure to red blood cell transfusion, anemia, or both? J Thorac Cardiovasc Surg. 2013;146:1480-7.

6. Ranucci M, Pavesi M, Mazza E, Bertucci C, Frigiola A, Menicanti L, et al. Risk factors for renal dysfunction after coronary surgery: the role of cardiopulmonary bypass technique. Perfusion. 1994;9:319-26.

7. Bhaskar B, Dulhunty J, Mullany DV, Fraser JF. Impact of blood product transfusion on short and long-term survival after cardiac surgery: more evidence. Ann Thorac Surg. 2012;94:460-7.

8. Engoren MC, Habib RH, Zacharias A, Schwann TA, Riordan CJ, Durham SJ. Effect of blood transfusion on long-term survival after cardiac operation. Ann Thorac Surg. 2002; 74:1180-6.

9. Arora RC, Légaré J-F, Buth KJ, Sullivan JA, Hirsch GM. Identifying patients at risk of intraoperative and postoperative transfusion in isolated CABG: toward selective conservation strategies. Ann Thorac Surg. 2004;78: 1547-54.

10. Ferraris VA, Brown JR, Despotis GJ, Hammon JW, Reece TB, Saha SP, et al; Society of Thoracic Surgeons Blood Conservation Guideline Task Force. 2011 update to the Society of Thoracic Surgeons and the Society of Cardiovascular Anesthesiologists blood conservation clinical practice guidelines. Ann Thorac Surg. 2011;91:944-82.

11. Xydas S, Magovern CJ, Slater JP, Brown JM 3rd, Bustami R, Parr GV, et al. Implementation of a comprehensive blood conservation program can reduce blood use in a community cardiac surgery program. J Thorac Cardiovasc Surg. 2012;143:926-35.

12. Alghamdi AA, Davis A, Brister S, Corey P, Logan A. Development and validation of Transfusion Risk Understanding Scoring Tool (TRUST) to stratify cardiac surgery patients according to their blood transfusion needs. Transfusion. 2006;46:1120-9.

13. Bennett-Guerrero E, Zhao Y, O'Brien SM, Ferguson TB Jr, Peterson ED, Gammie JS, et al. Variation in use of blood transfusion in coronary artery bypass graft surgery. JAMA. 2010;304:1568-75.

14. McQuilten ZK, Andrianopoulos N, Wood EM, Cole-Sinclair MF, McNeil JJ, Cameron PA, et al. Transfusion practice varies widely in cardiac surgery: results from a national registry. J Thorac Cardiovasc Surg. 2013;147: 1684-90.

15. Surgenor D, Churchill W, Wallace E, Rizzo RJ, McGurk S, Goodnough LT, et al. The specific hospital significantly affects red cell and component transfusion practice in coronary artery bypass graft surgery: a study of five hospitals. Transfusion. 1998;38:122-34.

16. Jin R, Zelinka ES, McDonald J, Byrnes T, Grunkemeier GL, Brevig J. Effect of hospital culture on blood transfusion in cardiac procedures. Ann Thorac Surg. 2013;95:1269-74.

17. Goodnough L, Johnston M, Shah T, Chernosky A. A two-institution study of transfusion practice in 78 consecutive adult elective open-heart procedures. Am J Clin Pathol. 1989;91:468-72.

18. Shehata N, Wilson K, Mazer CD, Tomlinson G, Streiner D, Hébert P, et al. The proportion of variation in perioperative transfusion decisions in Canada attributable to the hospital. Can J Anesth. 2007;54:902-7.

19. Zaffar N, Joseph A, Mazer CD, Nisenbaum R, Karkouti K, Tinmouth A, et al. The rationale for platelet transfusion during cardiopulmonary bypass: an observational study. Can J Anaesth. 2013;60:345-54. 